\title{
ORIGEN Y FORMACION DE LA LENGUA CATALANA
}

Manuel Antonio Quirós R.

\section{Situación del catalán actual}

El catalán es una lengua romance occidental asentada, junto con el español y el gallego-portugués en Iberorromania. Se divide en catalán occidental: Andorra, zona oriental de Aragón, Lérida (la capital), este de Tarragona y la región de Valencia; y en catalán oriental: Departamento francés de los Pirineos (Rosellón), Gerona, Barcelona (la capital), norte de Tarragona, Islas Baleares y Alguero, en Cerdeña.

\section{Rasgos diferenciadores de ambas formas de catalán}

Latín

catalán escrito

MANDARE SENTIRE

manar

sentir

\section{catalán occidental}

maná

sentí

\section{catalán oriental}

məná

sạntí (1).

\section{La unidad del catalán}

El catalán es la lengua romance con mayor unidad dialectal, debido a los siguientes factores:

1. La autoridad de escritores, como Jacinto Verdaguer;

2. la intervención de filólogos y gramáticos, como Pompeu Fabra;

3. el estudio de la lengua literaria medieval y de la renacentista;

4. Ia integración de las realidades dialectales, y

5. el predominio de las modalidades lingü ísticas barcelonesas, que han logrado imponerse entre la juventud de Valencia y de Palma de Mallorca.

\section{La presencia del latín en las lenguas romances.}

Las lenguas y dialectos romances constituyen variedades lingüísticas procedentes del latín, no sólo en su vocabulario, sino, lo más importante, en su estructura morfosintáctica.

El latín fue importación e "imposición" de una gran potencia, ROMA, y forma el elemento nacional y autóctono de cada variedad románica. No obstante que en ninguna lengua neolatina no se dé la "pureza" absoluta, se podría afirmar exageradamente que una lengua romance es tanto más pura

cuanto más se asemeje al latín; con todo, no se debe olvidar que éste, aun el clásico, tampoco es puro, pues también el elemento extranjero intervino en su constitución. (¿Qué hubiera sido del latín sin el griego?) (2). Por ser la lengua de Roma el elemento primoridal de las lenguas neolatinas, es la parte esencial de éstas, el estrato.

El conjunto de naciones, territorios y áreas en donde se empleaba o emplea un dialecto o una lengua romance constituye la Romania, y así como en Roma y en su imperio se empleaba el latín, en Romania se usa el neolatín. El sustantivo romance se deriva del adverbio latino romanice ('románicamente'), procedente de Romania, una ampliación de Roma.

Desde la perspectiva lingüística, Romania se divide en oriental: rumano, dalmático e italiano; y en occidental: retorromance (ladino), provenzal (occitano o "langue d'oc"), francoprovenzal, francés ("langue d'oil"), gascón, catalán, castellano (español) y gallego-portugués.

Las tres últimas lenguas con sus respectivos dialectos forman la Iberorromania, una identidad histórico-geográfica poseedora de variedades neolatinas que se asentaron sobre los sustratos prerromanos, sobre todo ibéricos.

Una lengua es una y única; con todo, posee ramificaciones, afluentes del mismo río, según su empleo socio-cultural. El latín tiene dos funda- 
mentales: el clásico, empleado por los escritores, y el vulgar, hablado por el pueblo, incluidas las personas cultas. El primero se continuará en la Edad Media bajo el nombre de latín medieval (laico, o eclesiástico). El segundo, por circunstancias particulares, se perpetúa en las distintas variedades romances.

No obstante, el latín culto (clásico) siempre ha estado presente en las lenguas románicas mediante el fomento inspirado en el recuerdo de Roma; por la Iglesia Católica, esencialmente romana (en su aspecto externo), el "lus Romanum", el Renacimiento Carolingio, el Renacimiento de Europa del siglo XV, ciertas universidades (en nuestro país, la Universidad de Costa Rica y el Studium Generale de la Universidad Autónoma de Centroamérica), algunos liceos "clásicos" europeos, y por toda una pléyade de escritores, desde la Edad Media, quienes, siempre que fuese menester, recurrían al latín ciceroniano como fuente inspiradora de cultismos, semicultismos, tecnicismos y neologismos.

Se conoce como superestrato cultural latino la presencia y acción influyentes del latín culto sobre los romances. (Mención marginal merecen el latín cristiano, una "Sondersprache" (3), -caracterizado por su semántica- empleado en los primeros siglos del Cristianismo por un reducido grupo de personas, y el latín humanista de los siglos XIV y $\mathrm{XV})$.

\section{Algunos préstamos prerromanos en catalán.}

Lingüísticamente, en la formación de una lengua se debe tomar en consideración el sustrato, estrato, adstrato y superestrato.

Trazaremos el origen y desarrollo de la lengua catalana desde las variedades prelatinas (lenguas asentadas en la Península Ibérica a la llegada de los romanos, 218 a. C.) hasta el siglo XIV:

\section{Lenguas de sustrato}

Con referencia a Hispania, las lenguas de sustrato son las que se hablaban en la Península Ibérica antes de la imposición del latín; todas, excepto el vasco, fueron eliminadas por aquél; mas, no obstante su desaparición, dejaron algunos préstamos fonéticos y lexicales en la lengua dominante, los cuales desembocaron en las lenguas continuadoras del latín. Algunas lenguas de sustrato son: el vasco-ibero, el celta, el ligur, el fenicio y el griego. a. Préstamos del vasco-ibero: Andorra, esquerra (izquierda), gerdo (franbuesa), pisarra, sarna, etc.

b. Préstamos del celta: Balanguer, balec (junco), balma, Besalu, cabanya, camisa, carro, los sufijos -ac, - $a c u$, -briga (fortaleza): Segobriga $>$ Segorbe; y -dunu (ciudad, cf. ingl. town), etc.

c. Préstamos del ligur: suf. -ascu (Benasque).

d. Préstamos del fenicio: Ebusus > Ibiza.

e. Préstamos del griego: de mucho mayor importancia y utilidad son los préstamos dados por el griego, pues permitió que el latín (en un principio lengua de pastores y de campesinos) Ilegara a ser instrumento apto para la expresión filosófica, filológica y literaria.

La historia de la penetración de los helenismos en las lenguas romances es variada y compleja. Algunos medios por los que se llevó a cabo son los siguientes:

La colonización griega en las costas del Mediterráneo del levante hispánico: Ampurias, Denia, Rosas y Sagunto. (En este primer aspecto, la acción del griego fue superficial).

El latín vulgar: botiga (bodega), colp (golpe), tía, etc.

El latín clásico: gramàtica, filosofia, retòrica, tragèdia, etc.

El latín cristiano: àngel, església (iglesia), evangeli (evangelio), etc.

El latín medieval: bólos > bol 'Ianzamiento de las redes'. (En este caso, los préstamos se deben a las relaciones político-comerciales de la Corona de Aragón con Grecia).

El árabe: ambi > alambí, etc.; y

los neologismos y tecnicismos, términos de reciente creación, para la terminología especializada de las ciencias y de la técnica.

\section{Roma e Hispania}

La situación de los pueblos peninsulares en el momento de la llegada de los romanos a su suelo era caótica: la unidad política, religiosa, cultural y lingüística era inexistente; el pueblo o la raza débil se encontraba a merced del más prepotente. Roma le logró poner coto a tal situación: en el siglo III a. C., los púnicos logran dominar a los iberos, éstos Ilaman en auxilio a Roma; ésta efectúa su primer desembarco, bajo el mando de Escipión, en lo que sería poco después la Provincia Tarraconensis 
(218 a. C.). Roma, ya en camino de convertirse en potencia, no se irá de Hispania, e impondrá, mediante la romanización, una cierta unidad cultural; por medio de la latinización, una cierta unidad lingü ística; por el Derecho Romano, la unidad jurídica, y más tarde, merced al cristianismo, una cierta unidad religiosa. ( $\mathrm{iHe}$ aquí cuatro unidades que todavía constituyen la esencia del mundo occidental, sobre todo del románico!).

Luego de que los romanos pusieron pie en Iberia, fundaron dos provincias: la Tarraconensis, por donde habían entrado, y la Baetica, en el sur; ambas, principalmente la segunda, fueron muy romanizadas, lo cual es efecto del interés de la Urbs por Hispania, baluarte del romanismo, según Mommsen; de hecho, ella fue una de las primeras conquistas con un fuerte grado de aculturización romana.

No obstante los beneficios derivados de la romanización, el interés de la metrópoli, se centra (es natural) en la explotación y comercialización de minerales, que ocasionan un fuerte colonialismo, cuya consecuencia inmediata es el desvanecimiento de casi toda forma de vida autóctona y característica de los primitivos habitantes hispanos: astures, bastetanos, cántabros, carpetanos, celtas, galaicos, ilegertes, lusitanos, oretanos, vetones, etc.; todos carentes de unión y del principio regidor del derecho, sustituirán sus culturas, costumbres, lenguas y religiones por las importadas desde Roma. Esta se encargará de proporcionarles la unidad político-jurídica y la idiomático-cultural, con lo cual el latín logra ser implantado en sus dos aspectos esenciales: el clásico, para la modalidad escrita, y el vulgar, para la expresión oral.

7. El latín, estrato de las lenguas romances, y por ende, del catalán.

El origen potencial de las lenguas romances se encuentra en la implantación del latín vulgar en casi todo el territorio de la Península Ibérica. El catalán también es parte del mundo románico; por tanto, metodológicamente es imposible proceder por separado sin tomar en cuenta las demás variedades neolatinas.

Que el catalán sea una lengua procedente del latín, se puede comprobar mediante las categorías gramaticales:

1) Artículos: el $<$ ille, la $<$ illam, els $<$ illos, les $<$ illas. Un $<$ unum, una $<$ unam, uns $<$ unos, unes $<$ unas.
2) Adjetivos calificativos: alt $<$ altum, bell $<$ bellum, clar $<$ clarum, formós $<$ formosum.

3) Numerales:

a) Cardinales: un $<$ unum, dos $<$ duos, tres $<$ tres, $<$ quatre $<$ quattuor, cinc $<$ quinque, sis $<$ sex, set $<$ septem, vuit $<$ octo, nou $<$ novem, deu $<$ decem, onze $<$ undecim, dotze $<$ duodecim, tretze $<$ tredecim, catorze $<$ quattuordecim, quinze $<$ quidecim, etc.

b) Ordinales: primer $<$ primarium, segon $<$ secundum, tercer $<$ tertiarium, quart $<$ quartum, quint $<$ quintum, etc.

4) Pronombres:

a) Personales: jo $<$ ego, tu $<$ tu, ell $<$ ille, nosaltres $<$ nos (alteros), vosaltres $<$ vos (alteros), ells <illos.

b) Demostrativos: aquest $<$ atque + eccum + iste, aqueix $<$ atque + eccum + ipse, aquell $<$ atque + eccum + ille.

c) Posesivos:

-Formas fuertes: meu $<$ meum, teu $<$ tuum, seu $<$ suum, nostre $<$ nostrum, vostre $<$ vostrum, llur $<$ illorum.

-Formas débiles: mon $<$ meum, ton $<$ tuum, son < suum.

d) Cuantitativos: quant $<$ quantum, molt $<$ multum, poc $<$ paucum, tant $<$ tantum.

e) Relativos: qui $<$ qui, que $<$ quid, (el) qual $<$ qualem.

5) Verbos en infinitivo: portar $<$ portare, saber $<$ sapere, dormir $<$ dormire.

6) Ejemplos de verbos conjugados:

Presente de indicativo: porto, portes, porta, portem, porteu, porten < porto, portas, portat, portamus, portatis, portant, respectivamente.

Imperfecto de indicativo: portava, portaves, portava, portávem, portáveu, portavan < portabam, portabas, portabat, portabamus, portabatis, portabant, respectivamente.

Ejemplo de una forma compuesta: jo he portat $<$ portatum habeo.

7) Conjunciones: ara $<$ hora, i $<e t$, malgrat $<$ male gratum, pero $<$ per hoc, que $<$ quid. 
8) Preposiciones: a $<a d$, de $<d e$, en $<$ in, entre $<$ inter, per $<$ per.

9) Adverbios: mes $<$ magis, molt $<$ multum, no pas $<$ non passum, segons $<$ secundum, també $<$ tam bene.

10) Sustantivos: arena < arena, germá < germanum, home $<$ hominen, senyor $<$ seniorem, cosa $<$ causa, , sol $<$ solem, lluna $<$ lunam.

\section{La transformación del latín en romance.}

¿Cuándo se operó la transformación del latín hacia los distintos romances? iHe aquí una pregunta con sólo respuestas aproximativas e hipotécas, pues las lenguas no poseen principio ni término fijos ni exactos! Las únicas fuentes más o menos seguras son los documentos escritos;pero éstos suponen cierta madurez, por lo demás tardía, en el empleo de una lengua.

De acuerdo con algunos romanistas, el año 476 (Caída del Imperio Romano de Occidente) marca sólo una fecha de referencia, pues las implicaciones políticas y sociales repercuten en lo educativo-cultural, que, a su vez, influye en los fenómenos de la lengua. Straka y Meillet fijan el siglo III, a partir del cual se da un proceso de diferenciación en cada provincia del imperio. Según Ferdinand Lot, en el siglo VI ya no se habla latín sino romance. Walther von Wartburg hace ver la importancia de las "Völkerwanderungen" (Invasión de los Bárbaros), por cuya acción el superestrato germánico queda fusionado con el latín de los siglos VII y VIII. En el 813, se realizaron en Francia dos concilios: el de Reims, que estipulaba la predicación en la lengua vulgar, y el Tours, que mandaba traducir las homilías en la rustica romana lingua: "Et quislibet episcopus habeat homelias... et ut easdem homelias quisque aperte transferre studeat in rusticam romanam linguam aut theotiscam, quo facilius cuncti possint intelligere quae dicuntur" (4). (Ya no tiene sentido predicar en latín, si el pueblo no lo entiende). No en vano las Glosas de Reichanau, también escritas en Francia, traen explicaciones bíblicas en un latín menos culto, aunque "correcto". En el 842, se escribió el primer texto en una especie de francés, seguido por el respectivo en una especie de alemán; el hecho histórico, por su parte, estaba en latín medieval de diplomas. Son los famosos Juramentos de Estrasburgo.

De 977 datan las Glosas Emilianenses, que, a la par de la palabra o de la frase latina, poseen aclaraciones en romance español.
Desde el siglo IX debió de darse la predicación en catalán, si pensamos en que hubiera sido acogida la disposición del Concilio de Maguncia, e incluida en los capitulares de los reyes francos con vigencia también para la región catalana.

Según nuestra opinión, el lapso del siglo $\mathrm{V}$ al siglo VIII es el más aproximativo en lo tocante al surgimiento de las variedades románicas. De hecho, en tal período comienzan a desaparecer los textos latinos, y en caso de escribirse, salen a la luz salpicados de algunas formas propias del romance: acento espiratorio, artículo, fusión del nominativo en el acusativo, futuro perifrástico, desaparición del ablativo absoluto y del acusativo con infinitivo, palabras con distinta semántica, etc. Ejemplos de tal latín es el merovingio de Francia y el notarial de España.

La unidad de la lengua de Roma, evidente en los siglos I y II de nuestra era, se disgregó lenta y gradualmente sin que nadie se percatara, una vez que se perdió el vínculo con la Urbs. Entonces, el latín vulgar de cada sitio y región comenzó a acentuar sus peculiaridades latentes, a lo cual contribuyó el aislamiento, que desembocarían irremediablemente en los distintos dialectos romances. Estos adquirirán más tarde otra especie de unidad, cuya manifestación será cada lengua romance estándar.

\section{La época visigótica y la disgregación del latín vulgar hacia el romance.}

El período visigótico se extiende del 414 al 711; por tanto, está comprendido entre el siglo $\mathrm{V}$ al VIII arriba especificado. (En la segunda fecha, Rodrigo, último rey visigodo, fue vencido por el árabe Tarik. Este les abrió a los moros las puertas del mediodía peninsular).

En tal período tuvo lugar la disgregación del latín vulgar hacia el romance hispánico.

¿Qué razones habrán tenido los visigodos para no imponer su lengua, de origen germánico? Al contrario, se romanizan y latinizan; esto es, acep$\tan y$ asimilan la cultura y la lengua latinas.

El romance visigótico se extiende del 414 al 711; es un latín vulgar hispánico muy romanceado dotado de algunas formas del superestrato visigodo. Lingüísticamente, el período visigótico se caracteriza por una unidad románico-hispánica, que, siglos después, será rota, en algunos aspectos, por el dialecto castellano. Así, el verbo clásico facěre (vulgar facēre) mantendrá la /f-/: catalán (fer), gallego-portugués (fazer), español antiguo 
(fazer). Aun más, tal /f $-/$ se conserva en toda la Romania: francés (faire), provenzal (faire), italiano (fare), rumano (face), sardo logurés (fágere), sardo engadés (fer), vegliota (fur) y friulano ( $f a)$. Pero el castellano se aparta al transformar tal / $f-/$ en $/ \mathrm{h}-\mathrm{l}$.

A partir de la Reconquista, la situación anterior comienza a sufrir diferenciaciones: el latín vulgar inicia un proceso más rápido y profundo de romanceamiento; entonces tiene lugar el protorromance ibérico, que en la época mozárabe se divide en mozárabe o romance suribérico y en romance nordibérico. Este originó el iberorromance occidental (gallego-portugués), el iberorromance central (astur-leonés-castellano) y el iberorromance oriental (catalán). - En la parte musulmana, el árabe constituía la lengua de la cultura, religión, y administración-. El latín medieval, por su parte, había sufrido un gran desprestigio, pues era un "latinum obscurum circa romancium" (5), lo cual equivale a un latín cuajado de "errores".

En el siglo $X$, por ejemplo, la situación lingüistica de la Península Ibérica se manifestaba así: árabe y latín medieval como lenguas de "cultura", respectivamente. En el norte, a partir del latín vulgar: gallego-portugués, asturiano-Jeonés, caste llano, navarro-aragonés y catalán. Al sur, en el territorio andaluz, se extendían los dialectos mozárabes, una continuación del romance visigótico y poseedores de formas árabes. Los dialectos mozárabes sucumbirán ante el avance arrollador (de norte a sur) del gallego-portugués, castellano y catalán. (Por ejemplo, el catalán de Valencia es mero producto de reconquista).

\section{Origen del catalán "in se".}

\section{1) Esbozo histórico antes del siglo VIII}

Con la llegada de los Romanos a la "Tarraconensis" en el 218 a. C., se asienta el latín en la región nordoriental de Iberia.

Desde el Imperio Romano comienzan las relaciones entre la Tarraconensis y la Narbonensis, ante todo, mediante el envio, de la segunda a la primera, de legionarios en disfrute de licencia militar.

Durante el período visigótico, los destinos de Provenza y de Cataluña pasan a manos de Ataulfo.

En el 711, los árabes tocan terreno ibérico y someten casi toda la península, excepto los focos de resistencia cristiano-visigoda que se van replegando hacia el norte para organizar e iniciar la Reconquista, la cual, una vez emprendida, tuvo los si- guientes rumbos: los castellanos (hacia el centro y sur), los portugueses (hacia el oeste) y los catalanes (hacia el este).

\section{2) Esbozo histórico desde el siglo VIII al XIV.}

Carlomagno establece marcas para defender el Imperio Franco contra los sarracenos. Del lado de España, la que guarda a Francia, es la Marca Hispánica, en la cual son acogidos muchos hispani en retirada de los moros. A partir de entonces, se estrechan los lazos de unión Cataluña y Francia.

Establecida la marca, lo primeró que hacen los francos es fundar varios condados y los incorporan al marquesado de Gotia o al de Tolosa, con lo cual se trae a Cataluña la organización política y administrativa carolingias, tanto civil como eclesiástica, que será guiada militar, civil, judicial y hasta financieramente por un conde, a quien también los obispos le deben guardar obediencia. Todos serán inspeccionados por los missi dominici, enviados personales del emperador.

Después de haber sido organizado feudalmente el Condado de Barcelona (o de Cataluña o la Marca Hispánica), sus primeros habitantes, quienes se habían refugiado allende los Pirineos, ya hablaban eso que sería el catalán, cuya primitiva sede, consecuentemente, se encuentra en las altas regiones norteñas entre ambas líneas de los Pirineos.

Luego tienen lugar los sucesivos movimientos de repoblación catalana desde el 759 al 801, año de la reconquista de Barcelona. En 765 fueron liberadas Gerona, Pallars y Ribagorza e incorporadas al marquesado de Tolosa.

La Marca Hispánica, asentada entre los Pirineos y el Llobregat, constituye la Catalunya Vella (Gerona, Ampurias, Barcelona, Ausona, Urgel-Cerdeña y Septimania). - Estas dos pasan a formar el marquesado de Gotia, aunque eclesiásticamente pertenezcan al Arzobispado de Narbona-.

El reino moro sureño más cercano a la Marca Hispánica es el de Tortosa; al oeste, el reino moro de Lérida.

Obtenida la libertad sarracena, los condes barceloneses no están contentos de seguir dependiendo del reino franco; dejan de reconocer la autoridad del Imperio Carolingio y establecen sus fronteras con el resto de Hispania en el Llobregat, al sur de Barcelona.

Fortalecida la Cataluña libre, los condes van a continuar lentamente con la reconquista y repoblación de su territorio. Luego, bajo Ramón Berenguer III, se consolida la unión de los condados. En 
1137, Ramón Berenguer IV contrae nupcias con Petronila, hija de Ramiro II de Aragón y heredera al trono, a partir de cuyo enlace, el Condado de Barcelona y el Reino de Aragón marcharán juntos en la historia catalano-aragonesa.

En 1230, aparece en escena una gran figura: Jaime I de Aragón, quien se apodera de Mallorca, Ibiza y Valencia, hasta Alicante, con lo cual éstas pasan a formar parte de la zona lingüística catalana, y no aragonesa, pues los aragoneses no quisieron participar con el Rey Conquistador.

Durante el reinado de Jaime I, el catalán queda constituido en lengua oficial del estado catalano-aragonés, y los reyes viven en Barcelona; pero se malograron grandes extensiones de algunos lugares que habían sido tomados por el Conquistador, dadas sus pretensiones al suelo occitano y la búsqueda del apoyo de nobles provenzales en la lucha contra la monarquía francesa, que, en virtud de la creación de la Marca Hispánica, reclamó para sí los territorios de la Casa de Barcelona.

De conformidad con las estipulaciones del Tratado de Corbeil, de 1258, se desistieron tales intereses y la frontera norte de Cataluña fue puesta en Cerdeña, Conflent y Rosellón. Entonces Barcelona y Aragón se lanzan a la mar en los siglos XIII y XIV y recogieron frutos: Córcega, Cerdeña, Sicilia, el Reino de Nápoles y el Ducado de Atenas.

La intervención catalana en el sureste francés (Provenza) hasta la Batalla de Muret (1213) trajo como consecuencia una ran admiración por la lengua y la literatura de los poetas trovadores occitanos. Hasta más, el catalán fue conocido como Ilengua lemosí (lengua lemosina).

En 1344, Pedro IV manda en sus Ordinacions... sobra lo regiment de tots los Officials de la sua cort, la manera "com se deu scriure a diverses persones, segons grau de cascun" (6).

\section{Algunos elementos de superestrato en cata- lán.}

Del siglo $\mathrm{V}$ al VIII el latín más o menos unitario del Imperio Romano se transformó en las distintas variedades neolatinas. A las voces procedentes de tal latín -romance infieri- se les conoce como patrimoniales o populares.

Cada lengua y dialecto romance desarrollará imperceptiblemente su propia manera de crear vocablos a partir del latín vulgar, explicables, a la vez, según las leyes de la gramática histórica.

Pero las lenguas y dialectos neolatinos no sólo representan estados evolutivos del latín vulgar, si- no que desde sus inicios incorporarán voces o préstamos procedentes de otras culturas. En la Edad Media, sobresalen los germanos y los árabes, cuya llegada a la Península Ibérica no logra aniquilar el neolatín; más bien, contribuyen a enriquecerlo mediante sus préstamos, conocidos bajo el nombre de superestrato.

\section{1) Germanismos del catalán.}

Los germanismos han penetrado en las lenguas romances indirectamente, a través del latín vulgar, o en forma directa en cada una de ellas, o por intermedio del francés y del provenzal:

a) Mediante el latín vulgar: desde el siglo II, Roma tenía contactos políticos, de buena vecindad con los pueblos germanos; esto permitió que muchos préstamos de estos se infiltraran en el caudal de la lengua hablada por los romanos, la cual se encargó de difundirlos entre las lenguas romances; por tanto, casi todos son préstamos comunes para toda la Romania. Aquí solamente tomaremos en consideración el catalán, el castellano, el francés y el italiano, respectivamente: blank $>$ blanc, blanco, blanc y bianco; frisk $>$ fresc, fresco, frais y fresco; heriberg $>$ alberg, albergue, auberge y albergo; hilm > elm, yelmo, heaume y elmo: orgoli $>$ orgull, orgullo, orgueil y orgoglio; riks $>$ ric, rico, riche y ricco, y werra $>$ guerra, guerra, guerre y guerra, con la correspondiente desaparición de las voces latinas: album, frigidum (recentem), deversorium, galeam, superbiam, divitem y bellum.

b) Por penetración directa en cada lengua romance: dado que los godos constituyen el más importante pueblo germánico penetrado en la Península Ibérica, vamos a tomar en consideración solamente este pueblo. En el 414 penetraron los godos en la Península Ibérica, y aceptan el romance en proceso de formación y hasta la religión oficial; por eso muchos visigotismos penetran imperceptiblemente en el neolatín ibérico:

-Antropónimos: Adefuns > Alfons (Alfonso), Alwar > Alvaro.

-Sufijos: -eng: aguilenc, negrenc.

c) Por intermedio del francés y del provenzal: brammon $>$ bramar, busc $>$ bosc (bosque), frank $>$ franc (franco), gaino $>$ ganar, hariwald $>$ herald (heraldo), want $>$ guant (guante), wardjan $>$ guàrdia, etc.

\section{2) Arabismos en catalán.}

Regían los visigodos casi toda Hispania y em- 
pleaban el romance visigótico, cuando he aquí que las huestes de Mahoma emprendían, en el 711, su "Guerra Santa". La dominación musulmana fue de diversa índole y duración en las comarcas catalanas: en la Catalunya Vella (7), los contactos con los moros fueron incidentales; mayores fueron en la Catalunya Nova (8).

El número de arabismos penetrados en catalán no es comparable con los introducidos en castellano; así, mientras el castellano usa una palabra árabe para determinado concepto, el catalán posee la voz correspondiente de procedencia latina.

De las 200 palabras catalanas de origen árabe, extraemos las siguientes:

a) Vocabulario: albarda, duana (aduana), rambla, sèquia (sequía), sofà, sucre (azúcar), tarifa, tassa (taza) y toronja.

b) Términos latinos arabizados: praecocum $>$ albercoc (albaricoque) y Caesar (u) gusta $>$ Saragossa.

c) Antroponimia: por ejemplo, el prefijo -ben, procedente de ben o beni o bini (hijo de): Benavides, 'hijo de Vidas'.

d) El prefijo árabe en -al: alforja, alferes (alférez), almirall (almiral). Sin embargo, al contrario del castellano y del portugués, su aglutinamiento con el respectivo sustantivo es menos común: carxofa (alcachofa), camfora (alcanfor), cotó (algodón).

e) El sufijo en -i: valencì (valenciano).

\section{Algunos elementos de adstrato en catalán.}

Los préstamos de adstrato son producto de las distintas relaciones culturales entre los pueblos. Los adstratos del catalán en la Edad Media son los siguientes:

1) El provenzal o lengua de oc. El occitano produjo una importante literatura durante la Edad Media por obra de los poetas trovadores, quienes cantaron, ante todo, el "Fins Amor" (el Amor Cortés). La lengua occitana fue el efecto de la evolución del latín vulgar importado en Galia por Julio César.

Por cercanía geográfica, y múltiples relaciones, fue natural que los catalanes admiraran e imitaran la cultura sureña de Francia y que el provenzal influyera en el catalán. Algunas palabras son: arma $<$ arma, aur $<$ aur, aquell $<$ aquel, jauzir $<$ jauzir.
2) El francés o lengua de oil. Los siguientes ejemplos constituyen algunos préstamos pasados del francés al catalán: frère $>$ frare (hermano), jardin $>$ jardí, hommage $>$ homenatge (homenaje), message $>$ missatge (mensaje), parage $>$ paratge (paraje), page $>$ patge (paje), viande $>$ vianda (carne).

3) El castellano. Los castellanismos en catalán se dieron por vecindad geográfica, penetración cultural y ser el castellano la lengua oficial de España. Los contactos del castellano con el catalán se acentúan a partir de 1137, fecha de la unión del Condado de Barcelona con la Corona de Aragón; por eso los reyes barceloneses fueron bilingües.

En la crónica sobre la reconquista de $\mathrm{M}$. de Montoliu, se encuentran estos castellanismos: levar < llevar, sobrino, soltar, el leísmo y la preposición 'a' más complemento directo.

Una vez que Aragón siguió los mismos destinos de Castilla (1479), se introducen hermoso $>$ hermós, guapo, hasta luego, ¿qué tal?, y muchas voces amerindias que el castellano había tomado de las lenguas del Nuevo Mundo: amaca, canoa, cacau, tomat, (tomate), etc.

(Dado que los préstamos del italiano penetraron en la lengua catalana desde los albores del Humanismo, y sobre todo en el Renacimiento, no se consignaron en este trabajo elementos italianos).

\section{3. "La questione della lingua catalana" (9).}

Durante los dos primeros siglos de creación literaria en Cataluña, se adoptó el provenzal, que se conoció bajo el nombre de Lemosí (principal dialecto en la formación de la "koiné" occitana) y fue tenido como una prolongación en territorio catalán, pues los Pirineos nunca han sido un obstáculo infranqueable para las relaciones franco-hispanas. Incluso, hacia el siglo XIV, troavadores catalanes, como Raimon Vidal de Besalú, Guillem, Vizconde de Bergadá, Guillem de Cabestany, Guerau de Cabrera y Guillem de Cervara, crearon poesías en provenzal.

Para explicar el desarrollo posterior del catalán al desmembramiento del latín vulgar, se han presentado tres teorías:

\section{1) La teoría galorrománica}

Para los defensores de esta teoría: E. Bourciez, A. Griega, W. Meyer-Lübke y G. Rohlfs, el provenzal fue transplantado a Cataluña en el siglo VIII a medida que avanzaba la reconquista; por tanto, 
opinan que el catalán es una prolongación del galorrománico en territorio ibérico.

\section{2) La teoría iberorrománica.}

Los seguidores de esta teoría, Amado Alonso, H. Morf, Ramón Menéndez Pidal y sobre todo J. Saraihandy, sin negar los contactos socio-culturales del provenzal con el catalán, dado el común origen latino y la vecindad geográfica, aseveran que no se puede negar el carácter iberorrománico del catalán, pues se debe tomar en cuenta el paniberorrománico, la continuidad lingüística románica desde Cataluña hasta Galicia, y no sólo el castellano. Por ejemplo, el castellano 'llorar' procede del latín plorare, cuya $/ \mathrm{pl}-$ / se mantiene no sólo en catalán y en provenzal sino también en Aragón y Navarra hasta Cantabria. Por tanto, la transición del provenzal hacia el castellano es gradual, pues no se debe desestimar el parentesco y parecido entre el catalán y el castellano a través del aragonés y del leonés. Por eso Menéndez pidal opina que el catalán es una lengua iberorrománica, aunque su destino haya sido decidido por la historia, pues desde Pepino el Breve y Carlomagno, forjadores del Imperio Carolingio, continuando con la invasión árabe y concluyendo con el inicio de la reconquista hispana, el territorio catalán ha gravitado hacia el norte de los Pirineos, de donde la influencia del provenzal.

\section{3) La teoría de la "lengua puente".}

Esta teoría es defendida por Badía Margarit y por Carlo Tagliavini (10). Para ambos, el catalán es una lengua romance situada geográficamente en España, pero con una orientación histórica y cul- tural hacia Francia, lo cual le proporciona semejanzas y diferencias con el iberorrománico, por una parte, y el galorrománico, por la otra. Su enclave especial la sitúa en una situación de "puente" de un sistema al otro; con todo, nuestra teoría le concede independencia lingü ística al catalán y le reconoce su rica literatura.

Nos adherimos a la tercera teoría y agregamos que la gravitación antigua del catalán fue hacia un centro cultural importante, Provenza, en Francia, pero la moderna lo es hacia otro centro cultural de renombre, Barcelona, en España.

La condición de lengua puente entre el galorrománico y el iberorrománico nos permite presentar ciertas afinidades del catalán con otras lenguas neolatinas, particularmente con el provenzal, francés y castellano.

\section{Afinidades del catalán con otras lenguas.}

\section{1) La afinidad románica.}

Siendo el catalán una lengua romance, presenta semejanzas fonéticas, morfológicas, sintácticas y lexicales, procedentes del mismo latín vulgar, con todas las lenguas romances. En la esfera lexical, según G. Rohlfs, existen muchas palabras en latín que han originado sendas voces en catalán, galorromance y castellano: sabucus, sauco (arbusto); magis, más; altus, alto; venter, vientre; patraster, padrasto; salire, salir; oblitare, olvidar; accucula, aguja; comparare, comparar; robur, roble; sartor, sastre; werra (de origen germánico), guerra; vivere, vivir; gallus, gallo; capritus, cabrito; equa, yegua y quod, que.

Las siguientes voces, son de origen latino y demuestran también tal afinidad del catalán:

$\begin{array}{llllllll}\text { Latín } & \text { catalán } & \text { castellano } & \text { portugués } & \text { francés } & \text { provenzal } & \text { italiano } & \text { rumano } \\ \text { paliam } & \text { palla } & \text { paja } & \text { palha } & \text { paille } & \text { palha } & \text { paglia } & \text { pai } \\ \text { foliam } & \text { fulla } & \text { hoja } & \text { fôlha } & \text { feuille } & \text { folha } & \text { foglia } & \text { foaie } \\ \text { rotam } & \text { roda } & \text { rueda } & \text { roda } & \text { roue } & \text { roda } & \text { rota } & \text { roata } \\ \text { focum } & \text { foc } & \text { fuego } & \text { fogo } & \text { feu } & \text { fuec } & \text { fuoco } & \text { foc } \\ \text { vitam } & \text { vida } & \text { vida } & \text { vida } & \text { vie } & \text { vida } & \text { vita } & \text { vita }\end{array}$

2) Afinidad del catalán con el provenzal

Probablemente el latín vulgar, base del catalán y del provenzal, fue bastante parecido; además, el

primero estuvo girando, desde el siglo VIII al XIII, hacia la órbita del segundo, lo cual incidió para que el catalán presente afinidades con el provenzal, según lo hacen ver los siguientes ejemplos: 
a) Vocabulario.

$\begin{array}{lll}\text { Latín } & \text { catalán } & \text { provenzal } \\ \text { februarium } & \text { febrer } & \text { febrier } \\ \text { fructum } & \text { fruit } & \text { fruit } \\ \text { murum } & \text { mur } & \text { mür } \\ \text { patrem } & \text { pare } & \text { paire } \\ \text { petram } & \text { pedra } & \text { peira } \\ \text { undam } & \text { ona } & \text { onda }\end{array}$

Los siguientes ejemplos, referentes al vocabulario, excluída la columna en latín, fueron extraídos de Estudios sobre el léxico románico, de Gerhard Rohlfs (11).

$\begin{array}{lll}\text { Latín } & \text { catalán } & \text { provenzal } \\ \text { adripare } & \text { arribar } & \text { arriba } \\ \text { ambulamus } & \text { anam } & \text { anam } \\ \text { avunculum } & \text { oncel } & \text { ouncle } \\ \text { bullire } & \text { bullir } & \text { boulí } \\ \text { cama } & \text { cama } & \text { camba } \\ \text { cremare } & \text { cremar } & \text { cremá } \\ \text { de mane } & \text { dema } & \text { demán } \\ \text { dies dominica } & \text { diumengue } & \text { dimenche } \\ \text { diesveneris } & \text { divendres } & \text { divendre } \\ \text { ficatum } & \text { fetge } & \text { fege } \\ \text { manducare } & \text { menjar } & \text { menjá, minjá } \\ \text { precare } & \text { pregar } & \text { pregá } \\ \text { plorare } & \text { plorar } & \text { plourá } \\ \text { pomum (pl. poma) } & \text { poma } & \text { pouma } \\ \text { racemun } & \text { rahim } & \text { rasin } \\ \text { res } & \text { res } & \text { res (ren) } \\ \text { spatula } & \text { espatlla } & \text { espala } \\ \text { tropare } & \text { trobar } & \text { trobá }\end{array}$

\section{b) Fonética}

- Carencia de diptongación de la /é́/ y de la /ŏ́/:

$\begin{array}{lll}\text { Latín } & \text { catalán } & \text { provenzal } \\ \text { mĕ́le } & \text { mel } & \text { mel } \\ \text { rŏtam } & \text { roda } & \text { roda } \\ & & \\ -|-0| \mathrm{y}|-\breve{\mathrm{u}}|>\phi & \end{array}$

$\begin{array}{lll}\text { amicum } & \text { amic } & \text { amic } \\ \text { caballum } & \text { cavall } & \text { cavall } \\ \text { quomo (do) } & \text { com } & \text { com }\end{array}$

- mantenimiento de la $/ \mathbf{f}-/$

feminam fembra fempna foliam fulla folha

$\begin{array}{lll}\text { clavem } & \text { clau } & \text { clau } \\ \text { flammam } & \text { flama } & \text { flama } \\ \text { plorare } & \text { plorar } & \text { plourá }\end{array}$

- Palatalización de /-lian-/ y de /-c'l-/

consilum consell conselh oculum ull uelh

\section{3) Afinidad del catalán con el castellano}

Por ser el catalán una lengua latina asentada en Iberorromania, posee también similitudes con el castellano; no obstante, en dicho parangón debemos tomar en cuenta la totalidad de los idiomas de la Península Ibérica; entonces notaremos la gradación, en cuanto al parecido, que se produce del catalán hacia el castellano principalmente en la Edad Media, cuando existía una línea continua entre el catalán, aragonés, leonés, restos del mozárabe, español antiguo y gallego-portugués. Por ejemplo, latín formiga; da catalán y provenzal formiga; koiné hispánica medieval, incluido el español antiguo, formiga; sólo el castellano, dialecto innovador, que destrozó tal unidad relativa, tiene hormiga; esto es, a la /f-/ latina propia de la totalidad de la Iberorromania corresponde la / $\mathrm{h}-/$ castellana.

a) Vocabulario

Latín catalán castellano

$\begin{array}{lll}\begin{array}{l}\text { Buccam } \\ \text { causam }\end{array} & \text { boca } & \text { boca } \\ \text { fortiam } & \text { cosa } & \text { cosa } \\ \text { honorem } & \text { força } & \text { fuerza } \\ \text { linquam } & \text { honor } & \text { honor } \\ \text { llengua } & \text { lengua }\end{array}$




$\begin{array}{llllll}\begin{array}{l}\text { magistrum } \\ \text { operam } \\ \text { originem }\end{array} & \begin{array}{l}\text { maestre } \\ \text { obra }\end{array} & \begin{array}{l}\text { maestro } \\ \text { obram }\end{array} & \text { Latín } & \text { francés } & \text { catalán } \\ \text { origen } & \text { origen } & \text { Non...passum } & \text { ne...pas } & \text { no...pas } \\ \text { populum } & \text { pedra } & \text { piedra } & \text { punctum } & \text { point } & \text { punt } \\ \text { regem } & \text { poble } & \text { pueblo } & & \text { francés } & \text { catalán } \\ \text { seniorem } & \text { rei } & \text { rey } & \text { Francón } & & \text { gaire } \\ \text { senyor } & \text { señor } & * \text { Waigaro (mucho) } & \text { guère } & \text {. }\end{array}$

b) Fonética

Monoptongación de /-au/ a /-o/

Causam

$\cos a$

$\cos a$

Palatalización de $/-\mathrm{nn}-/$ a $/-\tilde{n}-/$ y de $/-11-/$ a $/-! !-\mid$

$\begin{array}{lll}\text { Annu } & \text { any } & \text { año } \\ \text { caballu } & \text { cavall } & \text { caballo }\end{array}$

\section{c) Morfología}

En catalán como en castellano no se da el sistema bicasual (nominativo y acusativo), propio del latín vulgar; sí perdurará en langue d'oc (occitano).

\section{4) Afinidad del catalán con el francés}

Para comparar el catalán con el francés, solamente se toma en consideración un texto moderno escrito por Joan Corominas (12).

\section{Catalán}

"...Un altre mèrit, i no pas el més petit, de la reforma fabriana, és el d'haver produít una llengua literària acceptable a totes les regiones on es parla l'idioma..."

\section{Francés}

"...Un autre mérite, et pas le plus petit, de la réforme fabrienne, est celui d'avoir produit une langue littérarire acceptable pour toutes les régions où l'on parle la langue..." (13).

Con todo, no queremos pasar por alto el sistema de negaciones reforzadas propias del francés y del catalán:

\section{El superestrato cultural latino}

Constituidas las lenguas romances, cuyo proceso evolutivo esencialmente se extiende del siglo $\mathrm{V}$ al siglo XII, el latín culto nunca ha cesado de recurrir en su auxilio mediante la labor de los escritores y académicos, los distintos renacimientos, las instituciones jurídicas, los liceos "clásicos", las universidades y la Iglesia Católica Romana. Por ejemplo, cada vez que un escritor en romance necesitaba un término preciso, que no podía ser suministrado por su lengua materna, recurría al latín y simplemente lo copiaba o lo adaptaba a la idiosincracia de ésta.

A las influencias perennes del latín sobre las lenguas romances se les conoce con el nombre de superestrato cultural latino; éste se manifiesta:

1) Latinismos: curriculum vitae, ibidem, memorandum, quorum, sic, etc.

2) Cultismos: miracle, drama, crisi, categoría, monarquía.

3) Semicultismos: títol (título).

4) Dobletes etimológicos. En estos, el término culto es tomado directamente del latín culto: radi (pop. raig), càtedra (pop. cadira), laic (pop. Ilec), y el popular se deriva directamente del latín popular por desarrollo espontáneo.

5) Neologismos (voces de creación reciente).

6) Tecnicismos (términos propios de una ciencia, o técnica): aeróstat, télefon.

16. Los dos textos más antiguos del catalán y el de otras lenguas romances.

El texto catalán más antiguo es una versión literal y fragmentaria del códice visigótico del "Forum Judicum" (Fuero Juzgo), conservado en un manuscrito del siglo XII. Posee algunas glosas interpretativas y su estructura es completamente catalana, en 
contraposición con las Homilias de Organyá, que, no obstante constituir un catalán estándar preliterario, son afines con el provenzal.

Las homilías datan del siglo XII, y el manuscrito es el 289 de la Biblioteca Central de Barcelona y fue descubierto por J. Miret i Sans: "El mes antig texto literari escrit dels segles XI, XII, XIII", en los archivos de la Parroquia de Organyá, Diócesis de Urgel, Provincia de Lérida. Sus comentarios a textos latinos del evangelio no poseen pretensiones literarias, pues están destinados a los fieles cristianos para que comprendan y practiquen las enseñanzas evangélicas. Alguien se ha preguntado si no son alguna adaptación catalana de un sermonario provenzal.

El siguiente es un pequeño extracto: "Dominica in LX-a. In illo tempore, cum turba plurima convenirent et de civitatibus properarent ad lesum, dixit per similitudinem: Exit qui seminat seminare semen suum: Seinor, nostre Seinor dix aquesta paraula per semblant, et el esposa per si el ex. Aquel qui ix seminar la sua sement, e dementre que semenava, la sua sement cadeg prob de la via e fo calzigad, e.ls ocels del ciel mengaren aquela sement...".

Solamente insistimos en el aspecto bilingüe (latín-catalán) del texto, para resaltar cómo, en un cierto momento, el latín comienza a perder terreno ante cada lengua romance: en el 813 (fecha del Concilio de Tours) los obispos les pedían a sus sacerdotes que predicaran en romance: transferre in rusticam romanam linguam (traducir a la lengua romance), para que los fieles erudiantur (sean enseñados), capere et intelligere possint (y pueden captar y entender) la Palabra de Dios.

Los Serments d'Estrasbourg (Juramentos de (Estrasburgo primer documento galorrománico, poseen la introducción histórica en latín, seguida por los juramentos en sí pronunciados por Luis el Germánico en romana lingua (especie de francés antiguo), y por Carlos el Calvo en teudisca lingua (especie de alemán antiguo).

El texto más antiguo en romance italiano, I' $/ n$ dovinello Veronese (Ia Adivinanza Veronés), tiene, luego de la adivinanza, una acción de gracias en latín eclesiástico.

Las Glosas Emilianenses son aclaraciones en romance hispánico de palabras y oraciones en latín medieval.

Las Homilias de Organyá son textos extraídos del Evangelio, seguidos por prédicas en romance catalán.

Como se puede apreciar, los documentos anteriores son bilingües y representan el inicio de la gradual desaparición del latín en favor del romance.

\section{El triunfo del catalán.}

Desligado del latín, el romance catalán obtendrá su estandarización mediante la labor emprendida por Jaume I (Jaime I), quien lo hizo emplear en su cancillería. El es también el responsable de las cuatro crónicas tituladas Llibre dels feyts del rey en Jaume (14).

Precisamente, el ejemplo de Jaume I impulsó a Raimundo Lulio a elaborar su copiosa obra en catalán y no en latín. Este autor fue el primero en escribir asuntos serios en una lengua neolatina.

Dado que nuestro propósito era sólo presentar el idioma catalán (ver página 58, capítulo 5) desde sus orígenes hasta Raimundo Lulio, no mencionaremos a ningún otro escritor catalán.

En un resumen, el catalán es producto del latín vulgar asentado en la región hispánica nordoriental con cambios inherentes a cualquier sistema lingüístico, más los conflictos dialectales, y la influencia ejercida por los substratos, superestratos y adstratos de otros idiomas; entre estos sobresalen por su acción prestamista el provenzal y el castellano, que hacen del catalán una lengua puente entre el galorrománico y el iberorrománico.

Con todo, es el catalán una lengua poseedora de características propias y especiales, y, por tanto, independientes de los dos sistemas anteriores.

Finalmente, su relativa estabilización es fruto de su calidad de lengua de cultura dotada de grandes literatos. 

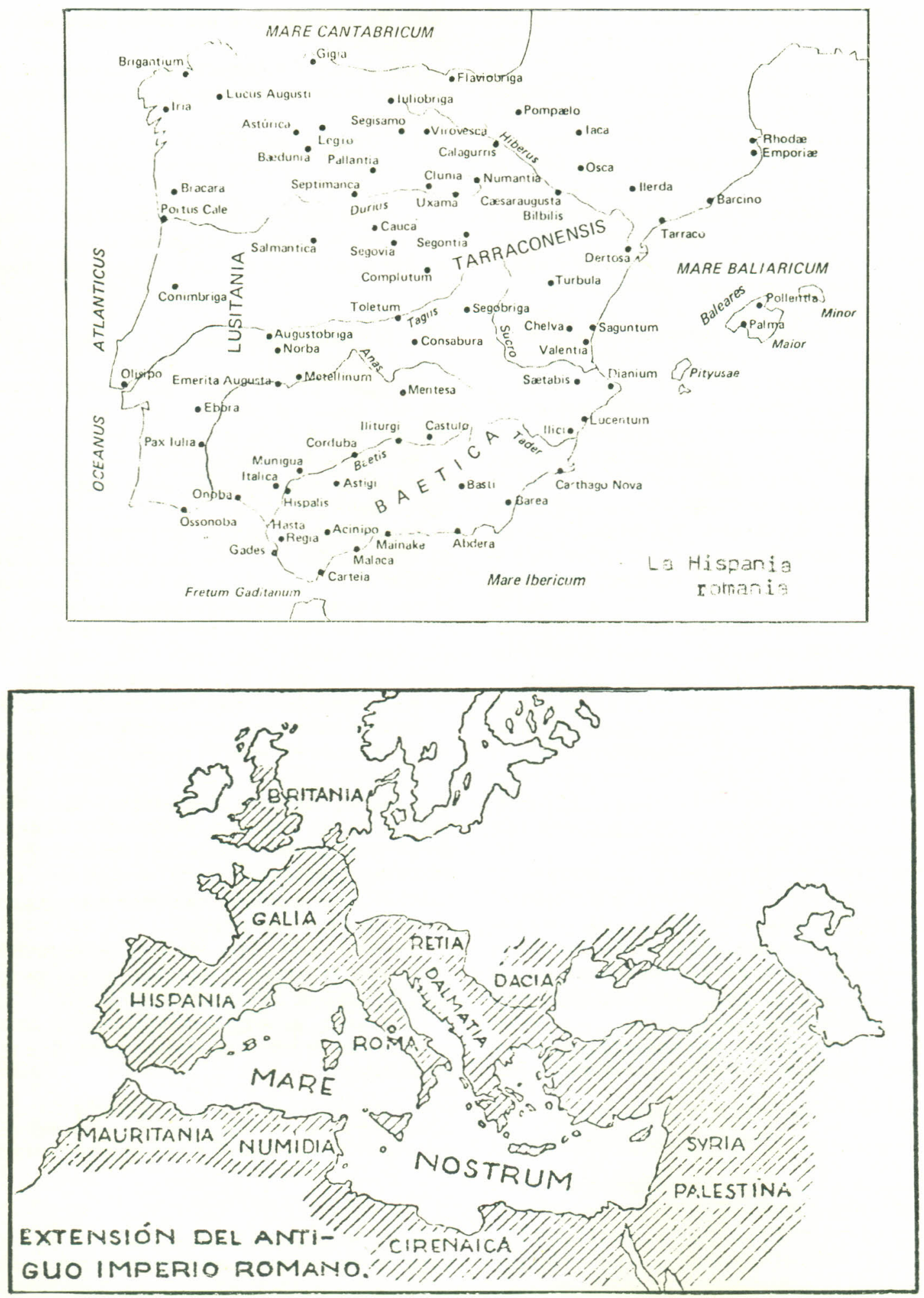


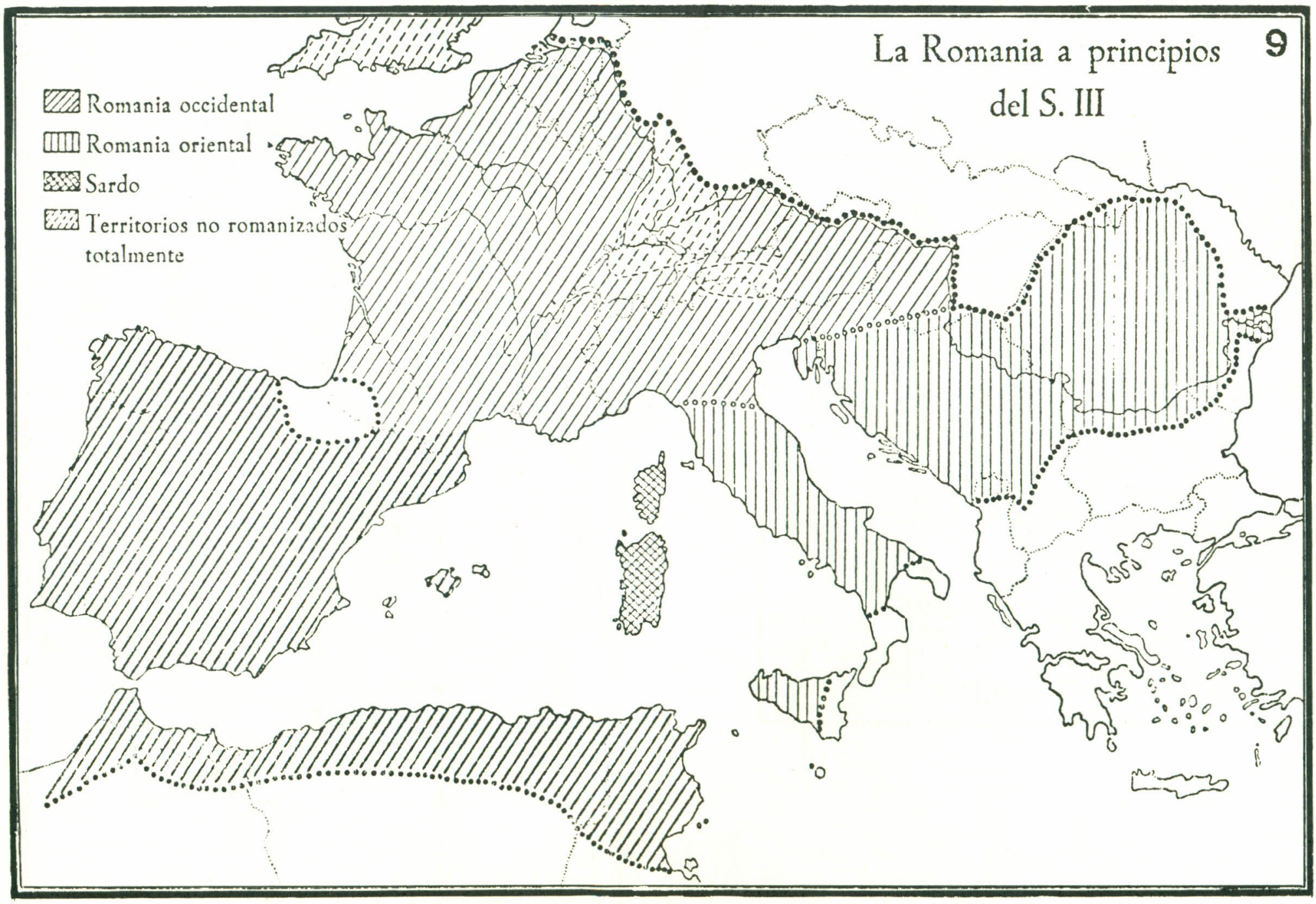




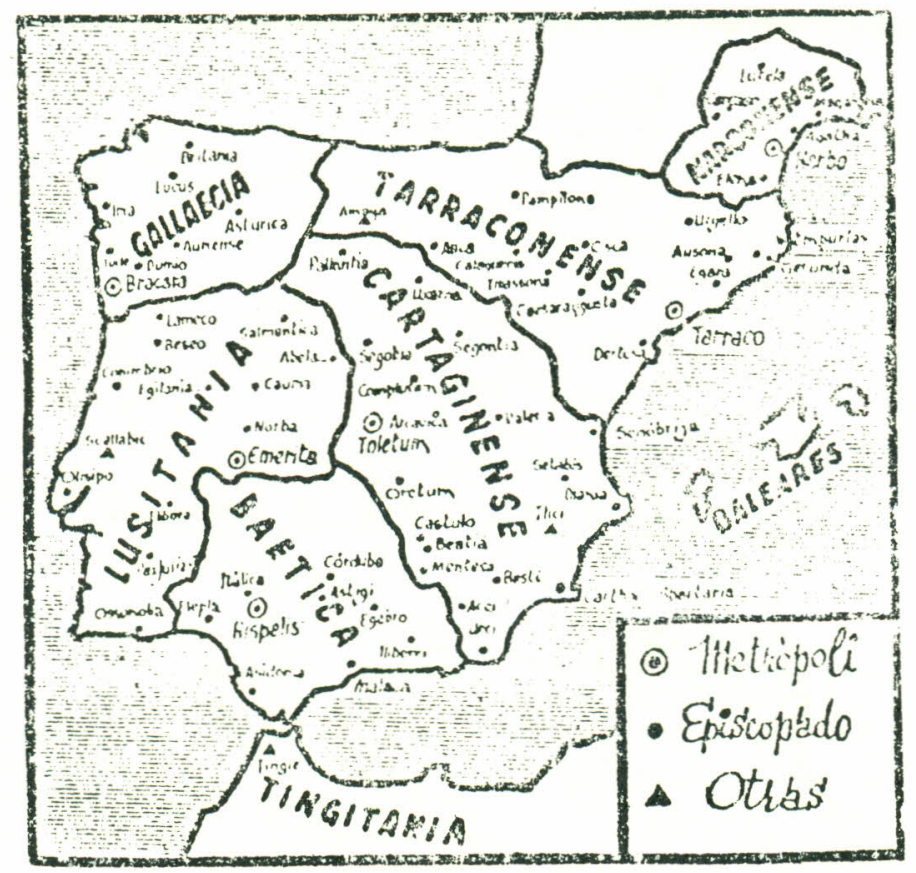

España visigoda

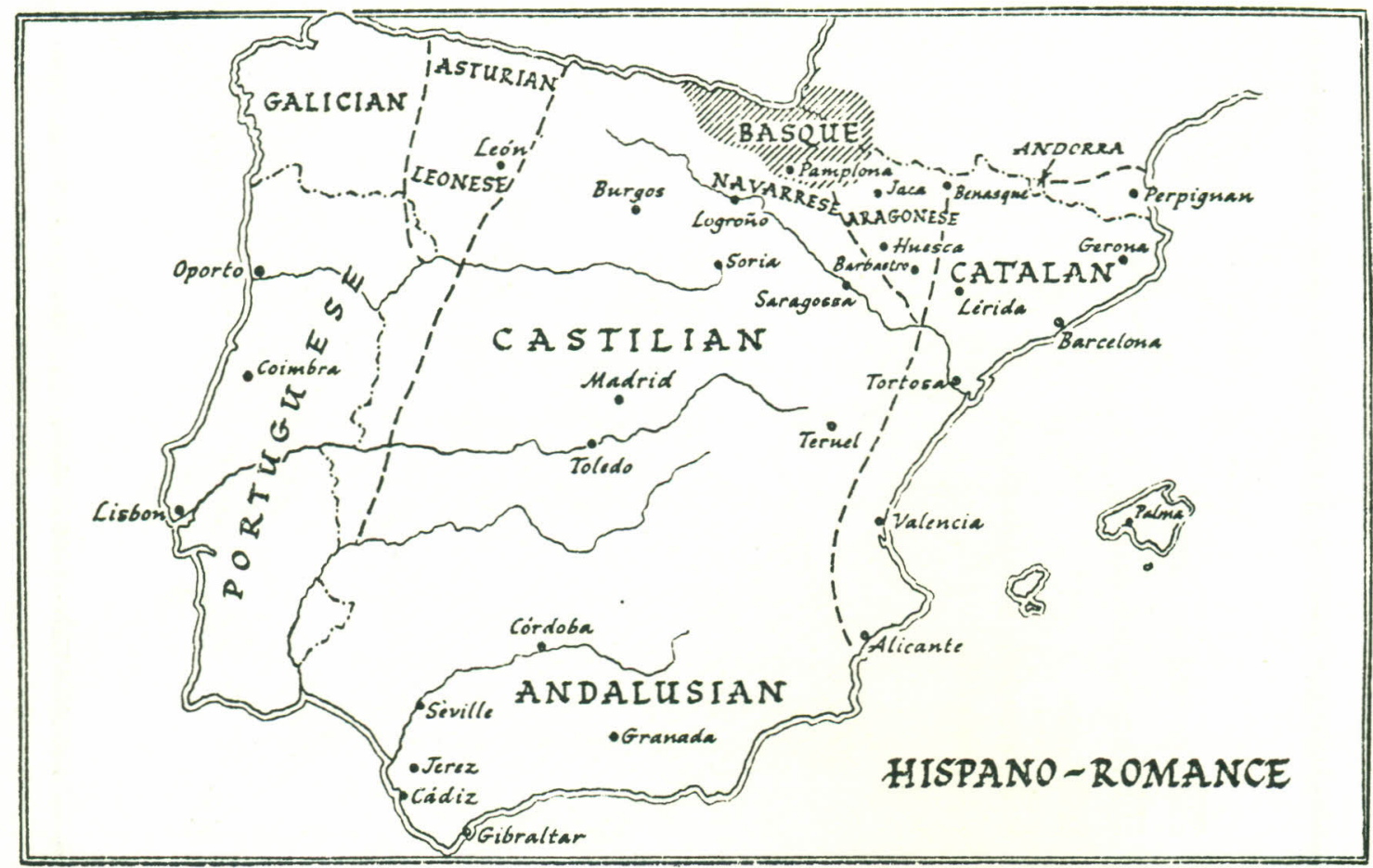




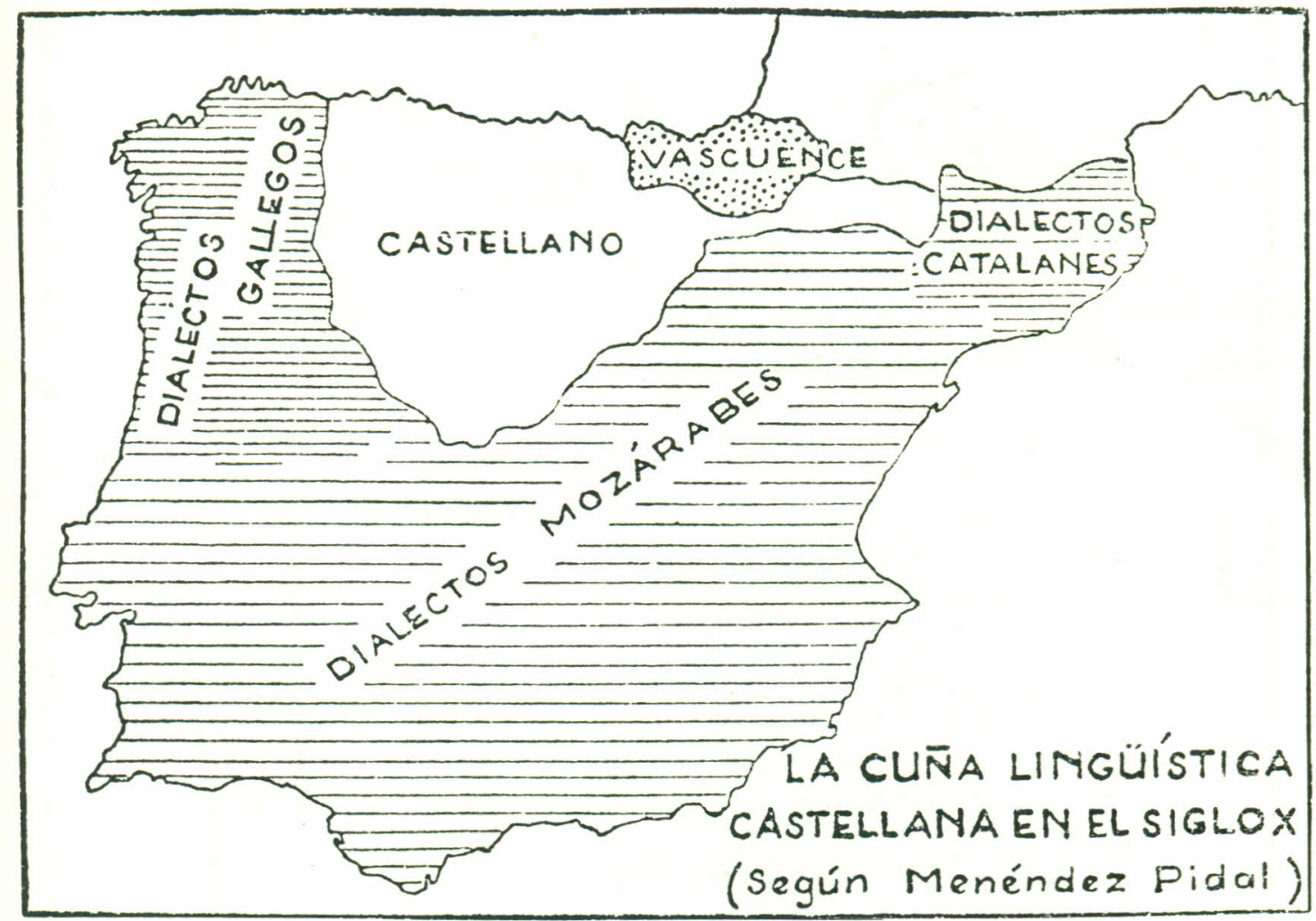




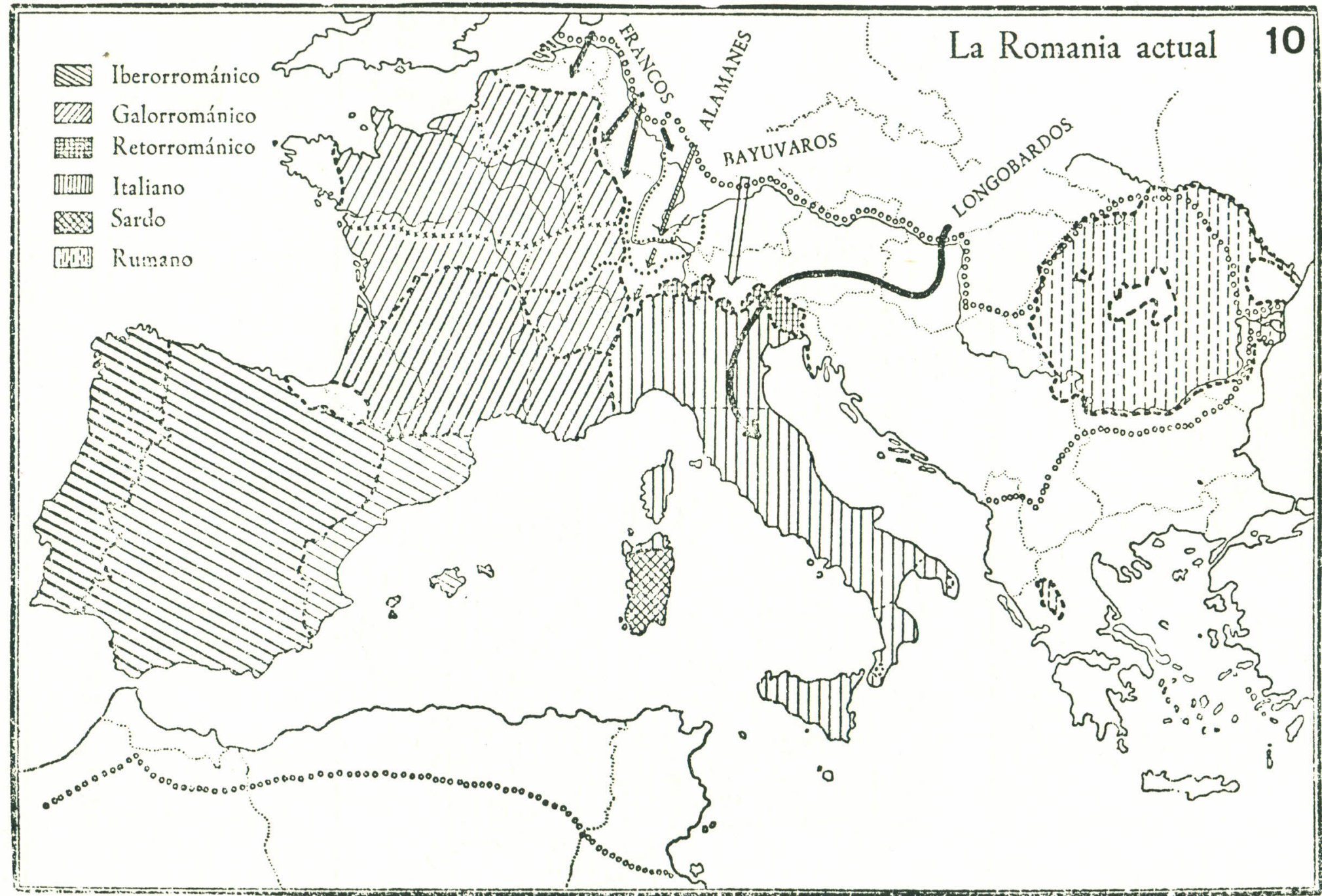

$\frac{\pi}{1}$
0
0
0
$\frac{\Omega}{D}$
$\alpha$
$\frac{5}{2}$
$\frac{\Omega}{\Omega}$
$\frac{5}{n}$
$\frac{1}{n}$
$\frac{\Omega}{8}$ 


\section{ANEXOS}

Libros de donde han sido tomados los mapas.

1) Segura Munguía Santiago, Latín 3o, Anaya 1977, pág. 49.

2) Díaz-Plaja Guillermo, El idioma español por la imagen y el ejemplo, Editorial Ciordia, Buenos Aires, 1971.

3) Von Wartburg Walther, La fragmentación lingüística de la Romania, Editorial Gredos,
Madrid, 1971, mapa no. 9.

4) Díaz-Plaja Guillermo, op. cit.

5) Elcock W. D., The romance languages, London, Faber \& Faber, 1960, pág. 14.

6) Díaz-Plaja Guillermo, op. cit.

7) Von Wartburg Walther, op. cit., mapa no. 10.

\section{NOTAS}

(1) Ejemplos tomados de B. E. VIDOS, Manual de Lingüística románica, Aguilar S. A. de Ediciones, Madrid, 1968, pág. 306.

(2) Nos hicimos esta pregunta, aunque retórica; pero es susceptible de dos interpretaciones.

(3) Traducción: lengua especial.

(4) Traducción: "Y cualquier obispo tenga homilías... y que cada quien se esfuerce en traducir tales homilías en la lengua románica vulgar o en la germánica, para que todos puedan comprender más fácilmente lo que se dice".

(5) Traducción: "Latín oscuro cercano al romance".

(6) Traducción: la manera "como se debe escribir a las distintas personas según la condición de cada uno".

(7) Catalunya Vella, la'Antigua Cataluña'.
(8) Catalunya Nova, la "Nueva Cataluña'.

(9) "La questione della lingua catalana", 'La cuestión de la lengua catalana'.

(10) La clasificación de las lenguas romances de Tagliavini se puede ver en: Orígenes de las lenguas neolatinas, Fondo de Cultura Económica, México, 1973, p. 478 .

(11) Gerhard Rohlfs, Estudios sobre el léxico románico, Ed. Gredos, Madrid, 1979, páginas 256 y 257.

(12) En Joan Coromines, El que s'ha de saber de la llengua catalana, Ed. Moll, Palma de Mallorca, 1965 , página 62.

(13) Traducción al francés realizada por el autor de este artículo.

(14) Traducción: "Libro de las hazañas del rey don Jaime".

\section{BIBLIOGRAFIA}

Badía Margarit, Antonio M., Gramática histórica catalana, Ed. Noguer, Barcelona, 1951.

Bourciez, Edouard, Eléménts de linguistique romane, Editions Kliencksieck, Paris, 1967.

Colon Domenech, German, Catalanismos, en: Enciclopedia Lingüística Hispánica, T. II, CSIC, Madrid, 1959, págs. 193-204.

Coromines, Joan, El que s'ha de saber de la llengua catalana, Ed. Moll, Palma de Mallorca, 1965.
Elcock, W. D., The romance languages, Faber \& Faber Limited, London, 1960.

Entwistle J. William, Las lenguas de España: Castellano, Catalán, Vasco y Gallego-Portugués. Ediciones ISTMO, Madrid, 1978.

Griega, A., Gramática histórica del Catalá Antic, Barcelona, 1931.

Lapesa, Rafael, Historia de la lengua española, Editorial Gredos, Madrid, 1980. 
Lázaro Carreter, Fernando, Diccionario de términos filológicos. Editorial Gredos, Madrid, 1971.

Lázaro Carreter, Fernando y Tuson Vicente, Curso de lengua española, Ediciones ANAYA, Madrid, 1979.

Metzeltin, Michael, Einführung in die hispanistische Sprachwissenschaft, Max Niemeyer Verlag, Tübingen, 1973.

Molas, Joaquín, Literatura catalana antigua, V.I, EI' Segle XIII, Editorial Barcino, Barcelona, 1961.

Moll, Francisco, Gramática histórica catalana, Editorial Gredos, Madrid, 1952.

Monteverdi, Angelo, Manuale d'avviamento agli studi romanzi, I e II, Ed. Vallardi, Milano 1952.

Quirós Rodríguez, Manuel A., "Castilla y el CasteIlano; origen de un lugar, un idioma y un nom- bre", en Revista de Filología y Lingüística de la Universidad de Costa Rica, V. 6 (1 y 2), págs. 81-97, 1980.

Rohlfs, Gerhard, Estudios sobre el léxico románico, Editorial Gredos, Madrid, 1979.

Roncaglia, Aurelio, La lingua del trovatori, Edizioni dell'Ateneo, Roma, 1965.

Tagliavini, Carlo, Orígenes de las lenguas neolatinas, Fondo de Cultura Económica, México, 1973.

Valles, Emili, Lliçons de gramàtica catalana, Llibreria Sinties, Barcelona, 1931.

Vidos,B. E., Manual de lingüistica románica, Editorial Aguilar, Madrid, 1968.

Von Wartburg, Walther, Die Ausgliederung der romanischen Sprachräume, Bern, 1950. 